

\title{
SCREENING OF MEDICINAL PLANTS FOR ANTIMICROBIAL ACTIVITY: PHARMACOGNOSY AND MICROBIOLOGICAL PERSPECTIVES
}

\author{
Michael Oluwole Osungunna \\ Address(es): \\ Department of Pharmaceutics, Faculty of Pharmacy. Obafemi Awolowo University, Ile-Ife, Osun State, Nigeria.
}

*Corresponding author: yomosun2002@yahoo.co.uk

doi: 10.15414/jmbfs.2020.9.4.727-735

\section{ARTICLE INFO}

Received 28. 10. 2018

Revised 30. 8. 2019

Accepted 2. 9. 2019

Published 3. 2. 2020

\section{Review}

open 2 access

\section{ABSTRACT}

The use of medicinal plants for human ailments precedes the introduction of conventional antibiotics. However, medicinal plants continue to enjoy human patronage because they are cheap, readily available and free from side effects often associated with conventional antibiotics. Reproducibility, on the part of screening plants for antimicrobial activity, has become a challenge both from the pharmacognosy and microbiology points of view. This review addresses the sampling techniques, phytochemical screening and the concept of metabolomics in relation to medicinal plants as well as the applicability and the advantages and disadvantages of some microbiological methodologies used in screening medicinal plants for their antimicrobial activity.

Keywords: Antimicrobial; screening; medicinal plants; microbiological; pharmacognosy

\section{INTRODUCTION}

Since the beginning of human culture, plants have been used by man for various purposes, especially for his survival and specifically, medicine. The application of medicinal plants all over the world precedes the introduction of antibiotics and other modern drugs. A medicinal plant can been defined as any plant which, in one or more of its biological structures, contains substances that can be used for therapeutic purposes or which are antecessors for the synthesis of useful drugs (Sofowora et al., 2013). Included in this definition are (i) plants or plant parts used medicinally in galenical preparations (e.g. decoctions, infusions, etc.) e.g. Cascara bark; (ii) plants used for extraction of pure substances either for direct medicinal use or for the hemi-synthesis of medicinal compounds (e.g. hemisynthesis of sex hormones from diosgenin obtained from Dioscorea yams); (iii) food, spice, and perfumery plants used medicinally, e.g. ginger; (iv) microscopic plants, e.g. fungi, actinomycetes, used for isolation of drugs, especially antibiotics. Examples are ergot (Claviceps purpurea growing on rye) or Streptomyces griseus; and (v) fibre plants, e.g. cotton, flax, jute, used for the preparation of surgical dressings (Evans, 2008; Sofowora, 2008). Medicina plants constitute a useful source of both traditional and modern medicines with herbal medicine having genuine utility upon which about $80 \%$ of the rural population depends as primary health care (Akinyemi et al., 2005). To identify and exploit aspects that provide safe and effective remedies for ailments of both microbial and non-microbial origins, the World Health Organization has advocated that countries should interact with traditional medicine (WHO, 1978) The use of medicinal plants is on the increase because of their relatively safe status, their wide acceptance by consumers, and their exploitation for potential multi-purpose functional use (Rodrigues et al., 2012). Also, increased resistance to conventional antibiotics by pathogenic microbes has made the search for new efficacious antimicrobial agents from plant source inevitable. Initial screenings of plants for possible antimicrobial effects typically start with the use of crude extractions (aqueous or alcohol) and can be followed by various organic extraction methods (Cowan, 1999). While some plants have been screened for their antimicrobial activity, many are being screened, and more will still be screened.

\section{Screening plants for antimicrobial effect: Pharmacognosy Perspective}

One problem that is often associated with screening plants for its activity/effect is the selection of material to be screened, otherwise known as sampling (Sofowora, 2008). Five approaches have been identified towards the selection of medicinal plants for screening. These include the random approach, phytochemical targeting approach, ethnobotanical survey approach, chemotaxonomic approach and blind screening of a plant's specific parts such as seeds, barks, roots, leaves and other plant parts (Farnsworth, 1966).

\section{Sampling of medicinal plants}

Medicinal plants to be screened for activity can be sampled randomly over a given area and data obtained thereof are collated for analysis to see the presence or otherwise of any meaningful pattern in the distribution of bioactive agents Identification of the plants is done before the commencement of the screening either at the time of collection or shortly after collection. The selection of plan material could be restricted to a particular family or genus known to contain a particular class of compounds (phytochemical targeting) or limited to those used in traditional medicine where a traditional practitioner helps in collecting data on local uses of the plants (ethnobotanical survey). With the phytochemical targeting approach, the investigator should be well acquainted with the diagnostic features of the family or genus with confirmed identification at the time of collection. However, an ethnobotanical survey requires that a specific plant be collected at the time the information is given preferably by the person volunteering the information, and their botanical names determined in a recognized herbarium where the specimen of the plant is also kept. All plants used for a given disease or ailment, or deemed to have the same pharmacological property are then screened for comparison of their activity. An ethnobotanical survey may also involve the use of herbaria data where the specimen of the plant is immediately available, and notes attached to herbarium sheets happened to be first-hand reports. It has been reported that plant sampling based on the ethnobotanical survey approach showed higher percentage amount of bioactive useful medicinal compounds over the other methods although targeted and random screening of plants and their extracts for effect have also produced excellent results (Khafagi and Dewedar, 2000).

Plants can be selected for screening based on their chemical constituents (chemotaxonomic approach) (Singh, 2016). Plants do produce secondary metabolites usually from the primary metabolites. The chemical structure of the secondary metabolites as well as their biosynthetic pathways, are always specific and restricted to taxonomically related plants. Chemotaxonomic approach to selection is advantageous in that fresh or complete materials are not the primary and compulsory requirements (Ankanna et al., 2012). Following the elaboration of the chemotaxonomic concept, plant taxonomy has become the most useful guide to a man in his search for new industrial and medicinal plants with chemical characteristics of plants most valuable to plant taxonomy (Singh, 2016). The advancement in analytical techniques for chemical analysis that can detect trace amount of chemical compounds has contributed to the rise of chemotaxonomy (Bhargava et al., 2013). However, sample collection or 
accessibility of the most promising plants as well as the identification of rare plants are some of the problems often encountered with this method.

Most often than not, blind sampling may be embarked upon to discover whether or not a plant possesses an activity and in which area of the pharmacological spectrum this activity lies. Blind sampling may be guided by the doctrine of Signatures or Similars developed by Paracelsus (1490 - 1541), a Swiss alchemist and physician. According to this doctrine, (i) nature has provided in every region plants for remedies which the diseases common to that region required for cure or treatment; (ii) nature has also provided signs or symbols to indicate by physical characteristics of the drug (colour, shape, taste) the diseases/disorders for which the plant is a remedy (Hocking, 1977). As a result, Sanguinaria (Bloodroot) was considered a blood remedy because of the latex' red, and so it was used for centuries on that basis; ginseng was used for debility because of the humanoid shape of the root (Chinese) (Hocking, 1977). Eyebright (Euphrasia officinalis, L) was used for the treatment of dim sight because the corolla of this plant has a dark purple spot resembling an eye (Sofowora, 2008). Extract of the leaves of Newbouldia laevis has been used to treat dental caries because the blade of the leaves of the plant resembles dentition (Amaechina, 2003). Also, plants with heart-shaped leaves were found useful for treating heart diseases, those with liver-shaped parts were prescribed for bilious diseases, and plants that are exuding a milky juice were believed to increase lactation in women.

\section{Phytochemical Screening}

Plants can be sampled using phytochemicals which are mainly secondary metabolites involved in defence against predators such as microorganisms, insects and herbivores. Sometimes, these metabolites give plants their odour, pigmentation and flavour and may serve to attract pollinators.

Secondary metabolites are also known to show curative activity against many ailments in humans and therefore could explain the rationale for the traditiona use of medicinal plants in the treatment of human illnesses. They are chemical compounds with complex structures and are more restricted in distribution than the primary metabolites. Nonetheless, they are not indispensable for the plants that contain them as their metabolic functions are yet to be discovered (Zhora et al., 2012).

Phenolic compounds are the most encountered secondary metabolites in the plant kingdom ( $\mathbf{L i}$ et al., 2006). Their structures can be as simple as phenolic acids or complex as tannins. Phenolic compounds include simple phenols (catechol, resorcinol etc), phenolic acids, stilbene (resveratrol etc), flavonoids (quercetin cyanidin etc), biflavonoids (ormocarpine etc), proanthocyanidins (epicatechin) (Wollenweber, 1986; Robards and Antolovich, 1997), tannins, coumarins and anthraquinones (Middleton and Kandaswami, 1986; Evans, 2008).

Phenolic acids can be described as hydroxylated derivatives of benzoic and cinnamic acids. The most encountered hydroxycinnamic acid derivatives are $\mathrm{p}$ coumaric, caffeic and ferulic acids, which often occur in food as simple esters with glucose or quinic acid (Mattila and Kumpulainen, 2002). Flavonoids comprise of a group of natural compounds that occur in vegetables, fruits, wine, chocolate tea, and other products of cocoa. Daily dietary consumption of flavonoids and similar polyphenols surpasses that of antioxidative vitamins and provitamins (Sies et al., 2005)

The following phytochemical tests can be carried out on the extracts (Tiwari et al., 2011; Zohra et al., 2012; Ben et al., 2013).

\section{Detection of alkaloids}

Extracts are dissolved individually in dilute hydrochloric acid $(\mathrm{HCl})$ and filtered. a) Mayer's Test: This involves treating the extract's filtrates with Mayer's reagent (potassium mercuric iodide). Alkaloids' presence is confirmed by the formation of a yellow coloured precipitate.

b) Wagner's Test: Addition of Wagner's reagent (iodine in potassium iodide) to the filtrates of the extract leading to the formation of brown/reddish precipitate confirms the presence of alkaloids.

c) Dragendroff's Test: Formation of red precipitate emanating from the treatment of the extracts' filtrates with Dragendroff's reagent (solution of potassium bismuth iodide) confirms the presence of alkaloids.

The alternative is to apply about $20 \mu \mathrm{L}$ of the ethanolic extracts on TLC plates (Silica Gel 60G, $5 \times 10 \mathrm{~cm}$ ) and elute with toluene-ethyl acetate-diethylamine $(70: 20: 10)$ as solvent system. The chromatogram is sprayed with Dragendorff's reagent and the spot where orange-brown colour develops indicates the presence of alkaloids (Wagner and Bladt, 2001).

d) Hager's Test: formation of a yellow coloured precipitate following the treatment of the extracts' filtrates with Hager's reagent (saturated picric acid solution) confirms the presence of alkaloids.

\section{Detection of carbohydrates}

Extracts are dissolved individually in $5 \mathrm{ml}$ distilled water and filtered. The filtrates are used to test for the presence of carbohydrates. a) Molisch's Test: Formation of the violet ring at the junction following treatment of the extract's filtrates with two drops of alcoholic $\alpha$-naphthol solution in a test tube confirms the presence of carbohydrates.

b) Benedict's Test: Filtrates are treated with Benedict's reagent and heated gently. Orange-red precipitate indicates the presence of reducing sugars.

c) Fehling's Test: Formation of red precipitate after the filtrates have been hydrolysed with dilute $\mathrm{HCl}$, neutralised with sodium hydroxide $(\mathrm{NaOH})$ and heated with Fehling's A \& B solutions confirms the presence of reducing sugars.

\section{Detection of glycosides}

Extracts are hydrolysed with dilute $\mathrm{HCl}$ and then subjected to a test for glycosides.

a) Modified Borntrager's Test: Ferric chloride solution is added to the extracts and followed by immersion in boiling water for about five minutes. The cooled mixture is extracted with equal volumes of benzene with separated benzene layer being treated with ammonia solution. The presence of anthranol glycosides is indicated by the formation of rose-pink colour in the ammonical layer.

b) Legal's Test: Formation of pink to blood red colour when extracts are treated with sodium nitroprusside in pyridine and $\mathrm{NaOH}$ indicates the presence of cardiac glycosides.

\section{Detection of saponins}

a) Froth Test: Extracts are diluted with distilled water to $20 \mathrm{~mL}$ and shaken in a graduated cylinder for 15 minutes. The presence of saponins is indicated by the formation of a $1 \mathrm{~cm}$ layer of foam.

b) Foam Test: $0.5 \mathrm{gm}$ of the extract is shaken with two milliliters of water Formation of persistent foam for ten minutes confirms the presence of saponins.

\section{Detection of coumarins}

This involves evaporation of about $5 \mathrm{~mL}$ of ethanolic extract followed by the dissolution of the residue in 1-2 mL of hot distilled water. The resulted solution is divided into two parts. To one part is added $0.5 \mathrm{~mL}$ of $10 \%$ ammonium hydroxide $\left(\mathrm{NH}_{4} \mathrm{OH}\right)$ solution. Both the treated and untreated portions are put on separate spots on the filter paper and examined under the UV light. Intense fluorescence of the treated portion spot indicates the presence of coumarins.

Alternatively, about $1 \mathrm{~g}$ of the extract can be placed in a test tube and sealed with filter paper wetted with dilute sodium hydroxide $(\mathrm{NaOH})$ followed by heating on a water bath for a few minutes. Intense yellow fluorescence under UV light indicates the presence of coumarins.

\section{Detection of phytosterols}

a) Salkowski's Test: Extracts are treated with chloroform and filtered. The filtrates are treated with few drops of concentrated sulphuric acid $\left(\mathrm{H}_{2} \mathrm{SO}_{4}\right)$ shaken and allowed to stand. The appearance of golden yellow colour indicates the presence of triterpenes.

b) Libermann Burchard's test: Extracts are treated with chloroform and filtered. The filtrates are treated with few drops of acetic anhydride, boiled and cooled Concentrated $\mathrm{H}_{2} \mathrm{SO}_{4}$ is added. Phytosterols' presence is confirmed by the formation of a brown ring at the junction.

\section{Detection of phenols}

Ferric chloride Test: Between 3 and 4 drops of $10 \%$ ferric chloride solution are added to the extracts. A bluish-black colour is formed if phenols are present.

\section{Detection of tannins}

Gelatin Test: One per cent $(1 \%)$ gelatin solution containing sodium chloride is added to the extracts. The presence of tannins is confirmed by the formation of white precipitate.

On the other hand, about $1 \mathrm{~mL}$ of the ethanol extract can be added to $2 \mathrm{~mL}$ of water followed by the addition of 2-3 drops of dilute ferric chloride solution in a test tube. Formation of green to blue-green coloration shows the presence of cathechic tannins while a blue-black coloration indicates the presence of gallic tannins.

However, the formation of a dark green or blue-green coloration when $2 \mathrm{~mL}$ of the aqueous extract is added to $2 \mathrm{~mL}$ of water followed by addition of 1-2 drops of dilute ferric chloride solution indicates the presence of tannins.

Alternatively, about $3 \mathrm{~mL}$ of the extract solution can be diluted with chloroform, followed by the addition of $1 \mathrm{~mL}$ of acetic anhydride in a test tube. About $1 \mathrm{~mL}$ of concentrated sulphuric acid is then added carefully by the side of the test tube to the resulted solution. Formation of a green color shows the presence of tannins. 


\section{Detection of flavonoids}

a) Alkaline Reagent Test: This involves adding a few drops of $\mathrm{NaOH}$ solution to the extracts. Presence of flavonoids is confirmed by the formation of intense yellow colour, which becomes colourless on the addition of dilute acid.

b) Lead acetate Test: This test is carried out by the addition of a few drops of lead acetate solution to the extracts. The presence of flavonoids is indicated by the formation of a yellow colour precipitate.

c) Shinoda's test: This involves the dissolution of about $1 \mathrm{~g}$ of the extract in $5 \mathrm{~mL}$ of ethanol $(98 \%)$ followed by the addition of a small piece of magnesium foil metal and a dropwise addition of concentrated hydrochloric acid. Formation of intense cherry red colour indicates the presence of flavonones while orange-red colour indicates the presence of flavonols.

\section{Detection of proteins and amino acids}

a) Xanthoproteic Test: Few drops of concentrated trioxonitrate v (nitric acid) are added to the extracts. Yellow colour is formed if protein is present.

b) Ninhydrin Test: Some volume of $0.25 \% \mathrm{w} / \mathrm{v}$ ninhydrin reagent is added to the extract and boiled for a few minutes. Blue colour is formed if an amino acid is present.

\section{Detection of diterpenes}

Copper acetate Test: This test involves dissolving the extracts in water followed by the addition of between 3 and 4 drops of a solution of copper acetate. Emerald green colour formation indicates the presence of diterpenes (Audu et al., 2007 Roopashree et al., 2008; Obasi et al., 2010).

Antibacterial activity of some plant extracts has been attributed to the presence of some of these phytochemicals as alkaloids (Damintoti et al., 2006), tannin (Banso and Adeyemo, 2007), saponins (Soetan et al., 2006), indole alkaloids (Tanaka et al., 2006) and anthraquinone (Sosa et al., 2006), among others.

It is, however, useful to register that the quality of an extract is a function of (i) plant part used as starting material (ii) the solvent used for the extraction and (iii) extraction procedure while the effect of extracted plant phytochemicals depends on (i) the nature of the plant material (ii) its origin (iii) degree of processing (iv) moisture content and (v) particle size (Ncube et al., 2008).

While various parts of plants such as root, bark, leaves can be used, the ultimate choice is a function of the part that gives the highest yield of the bioactive compound. Similarly, solvents as water, alcohol, chloroform, dichloromethane, ethyl acetate have been used in the extraction process. The choice is determined by factors like the quantity of phytochemicals to be extracted, the rate of extraction, range of different compounds extracted, multiplicity of inhibitory fractions extracted, ease of subsequent handling of the extracts, harmful effect of the solvent in the bioassay process and potential health hazard of the extractants (Eloff, 1998).

Extraction procedures vary from method to method in the length of extraction period, the solvent used for extraction, temperature, $\mathrm{pH}$ of the solvent, solvent/sample ratio and particle size of the plant parts (Das et al., 2010). Such methods include maceration, infusion, decoction, sonication, soxhlet extraction, digestion, plant tissue homogenization, serial exhaustive extraction and percolation.

More recent approaches to phytochemical screening have involved sophisticated instrumentation such as gas-liquid chromatography linked to mass spectrometry (GLC/MS) to study the minor alkaloids or to characterize the constituents of volatile oil-producing plants such as those in the family Labiatae. The introduction of high-pressure liquid chromatography (HPLC) has also made it possible for minor or thermolabile components of plant drugs to be isolated and characterized (Sofowora, 2008).

\section{The concept of metabolomics}

Phytochemical constituents (metabolites) of a plant can be affected by many factors such as the hour of the collection (diurnal variation), the season of the collection (seasonal variation) as well as location (geographical variation) However, the nature and quantity of metabolites present in a plant species at a point in time can be determined using the concept of metabolomics which has been defined as the study of the metabolite composition (i.e. the metabolome) of a cell type, tissue, organ, or organism (Patti et al., 2012). The term "metabolome" means the collection of endogenous small molecules that mark specific fingerprints of cellular biochemistry (Gowda et al., 2008).

The concept of metabolomics can be applied to the same species of the plant collected at a different time interval of the day; the same species of the plant collected at a different season of the year and the same species of the plant collected at different locations. Also, different species of plant with similar pharmacological action apart from different species of plant belonging to the same family can be subjected to metabolomic study. The metabolome often measured are usually low-molecular-weight metabolites that provide a snapshot of relevant biological processes including amino acids, fatty acids, organic acids, sugars, lipids, steroids, small peptides, and vitamins. It is worthy of note that questions that cannot be answered through proteomics, genomics and transcriptomics are usually answered with metabolomics, one of the -omics tetralogy.

Metabolomics can be targeted or untargeted depending on the objective, the level of quantification, the complexity of sample preparation, experimental accuracy and precision, as well as the number of metabolites detected. Untargeted metabolomics is defined as unbiased analysis of the metabolite composition of the biological entity in a specific physiologic state under given environmental conditions (Fiehn, 2002). It is, however, impossible to cover all metabolites in an unbiased manner bearing in mind the limitations of current analytic platforms and the conditions for sample collection and processing. With the knowledge of metabolite classes of biological interest, an appropriate analytic platform and method to enhance detection of metabolites of interest during sample preparation can be selected (Dunn et al., 2013). Also, no metabolite is identified prior to sample analysis. Despite technological advancement, many disadvantages are associated with untargeted metabolomics to include the need for a long time to process the extensive amounts of raw data, difficulties in identifying and characterizing unknown small molecules, reliance on the intrinsic analytic coverage of the platform used, and bias toward detection of high-abundance molecules.

However, a prior known subset of metabolites that are related by chemical structure, biological activity or both can be quantified using targeted metabolomics (Leung et al., 2013; Ioannidis and Khoury, 2011). This is made possible through the understanding of an array of metabolic enzymes, their kinetics, end products as well as the known biochemical pathways in which the set of metabolites partake (Robberts et al., 2012). A quantitatively reliable analytical method as triple quadrupole mass spectrometry makes quantification of low-concentrated metabolites that are difficult to detect possible, thereby minimizing bias towards low-abundance molecules (Patti et al., 2012). Bias can also be minimized through sample preparation to reduce high-abundance molecules dominance. The choice of metabolomics techniques should be based on the objective of the study, the type of sample, and resource availability.

Two primary analytical techniques often used for metabolomics include the nuclear magnetic resonance (NMR) and mass spectrometry (MS). However, while NMR generates spectral data that allow for quantification of the concentration and characterization of the chemical structure of metabolites; MS acquires spectral data in the form of a mass-to-charge ratio and a relative intensity of the ionized compound (Draper et al., 2009). Some separation techniques such as liquid chromatography (LC) and gas chromatography (GC) columns can be coupled to mass spectroscopy which in combination with good sample preparation increase the sensitivity and specificity of MS aside its good dynamic range, thereby makes it advantageous, especially for targeted metabolomics. NMR, on the other hand, is highly selective, highly reproducible, requires less sample preparation, and produces spectra that correlate directly and linearly with compound concentrations (Beckonert et al., 2007). However, NMR has relatively low sensitivity, and accordingly, only the most abundant species can generally be detected (Veenstra, 2012).

The success of metabolomics lies with adhering to some essential practice as itemised below:

1. All samples must be treated in the same manner for collection, processing and storage procedures (Bernini et al., 2011; Rosenling et al., 2011; Tzoulaki et al., 2014). This requires that all materials used such as the collection tubes, aliquot tubes and pipette tips be uniform in brand and type.

2. The sample must immediately be frozen while minimizing freezethaw cycles, contamination as well as differing methods of preservation. The process of immediate freezing will reduce a change in metabolic profiles (Teahan et al., 2006; Gika et al., 2007; Gika et al., 2008) and also prevent metabolites from being transformed very rapidly prior complete stoppage of enzymatic activity (Cuhadar et al., 2013; Yang et al., 2013).

3. The use of biospecimen repositories, with careful planning, especially for samples collected as part of large multipurpose studies, requires that samples have identical histories regarding the collection, storage, and processing.

4. Samples must be analyzed as early as possible while samples with freeze-thaw history should be avoided to prevent the potential loss of biomarker analytes (Bhatnagar et al., 2007; Cuhadar et al., 2013). This is because metabolites, like biological molecules, degrade over time, even when frozen.

5. Optimized and validated standardized metabolite extraction protocol tailored towards specific biospecimen type and metabolite species of interest is required for biological samples undergoing metabolomics analyses (Beckonert et al., 2007; Emwas et al., 2015). This may require additional steps to suppress any undesired noise, such as the presence of water, salt and protein, which can pose challenges depending on the analytic platform (Yin et al., 2015).

6. Studies that include longitudinal and recurrent sampling require that pooled quality control and blank samples be included with each filtration/extraction batch of samples to allow for variability monitoring in sample processing and acquisition (Broadhurst and Kell, 2006; Dunn et al., 2012). 


\section{Screening plants for antimicrobial effect: Microbiological Perspective}

\section{Antibacterial activity}

The term "antibacterial agent" can be defined as an agent whose activity is directed against bacteria. Generally, two major activities can be displayed by an antibacterial agent. The activity may be such that the growth of bacteria is inhibited in which case the agent is said to be bacteriostatic, and the agent itself a bacteriostat or that the bacteria are killed wherein the agent is bactericidal in activity and the agent a bactericide. Apart from this inherent difference, bacteriostatic activity is generally reversible in that when the bacteria are removed from the medium containing the agent into a recovery medium devoid of the agent, the growth of the bacteria resumes unlike a bactericide whose activity is not reversible (Lamikanra, 2002). However, when the antibacteria activity is directed against bacteria on an inanimate object, the process is called disinfection and the agent, disinfectant while when the activity is directed against bacteria on living tissues, the process is called antisepsis and the agent, antiseptic (Mcdonnell and Russell, 1999). Both antiseptic and disinfectant are generally referred to as biocides. Biocides, unlike antibiotics that act on specific structures or chemical processes in microbial cells, act non-specifically on multiple targets (Denyer and Stewart, 1998; Meyer and Cookson, 2010).

In nature, there exist no two pure categories of antibacterial agents (one that exclusively kills bacteria and another that only inhibits growth) (Pankey and Sabath, 2004). Instead, what determines if an antibacterial agent would be bacteriostatic or bactericidal include the conditions of growth, bacterial density (inoculum size), test duration, and the extent of reduction in bacterial numbers as well as in use concentration. For example, a bactericide at a lower concentration may exhibit only bacteriostatic activity while a bacteriostat used at higher concentration may have a lethal effect. This underscores the fact that the same agent can be used both as bacteriostat and bactericide but only at different concentrations. Similarly, if a bactericide that requires a longer contact time is allowed to act for a brief time may exhibit a bacteriostatic activity and a bacteriostat that is allowed to act for a very long time may eventually produce a killing effect. Majority of antibacterials are better described as potentially being both bactericidal and bacteriostatic (Pankey and Sabath, 2004).

\section{Mechanisms of Action of Antimicrobial Agents}

For an antibacterial agent to exert its action against bacteria, three conditions must be met: (i). susceptible antibacterial targets must exist in the cell, (ii). the antibacterial agent must reach the target in sufficient quantity and (iii) the antibacterial must not be inactivated or modified (Russell and Chopra, 1996
Sutcliffe
et
al.
1999).

Some of the established target sites with which antibacterial agents interact to exert actions include the cell wall, ribosome, nucleic acid as well as bacteria metabolic enzymes.

Some known mechanisms of antimicrobial action include (i) inhibition of peptidoglycan synthesis (e.g. $\beta$-lactams, glycopeptides), (ii) inhibition of protein synthesis (e.g. tetracyclines, chloramphenicol, mupirocin, macrolides, aminoglycosides-aminocyclitols), (iii) inhibition of nucleic acid synthesis by interrupting nucleotide metabolism (e.g. sulphonamides, diaminopyrimidines), (iv) inhibition of RNA polymerase (e.g. rifamycins), and (v) inhibition of DNA gyrase (e.g. quinolones). In addition, some antimicrobials interfere with membrane integrity (e.g. polymyxins) (Walsh, 2000; Russell, 2002). It is worthy of note that the majority of antimicrobial agents that inhibit protein synthesis are usually bacteriostatic while those that interfere with nucleic acid synthesis are often bactericidal.

In a nutshell, the type of antibacterial effect exhibited by the plant extracts can be used to predict the likely target(s) in the bacterial cell.

\section{Evaluation for antibacterial activity}

A bacteriostatic activity can be evaluated using the diffusion method, the dilution method, as well as bioautographic method. Bacteriostatic activity of an antibacterial agent can be quantified using the minimum inhibitory concentration (MIC) which has been defined as the minimum concentration of an antibacterial agent that will inhibit the growth of a named bacterium under a specified condition. An agent with low MIC value is more active than with high MIC value. It is essential to specify the bacterium and the conditions of the experiment because MIC is a function of the bacteria used, temperature, inoculum size as well as the medium used.

\section{Diffusion Method}

This method of evaluation uses the diffusibility of the antibacterial agent into the agar which is a function of the viscosity/concentration of the prepared antibacterial agent, the molecular weight of the agent, solubility of the agent, $\mathrm{pH}$ and ionization of the agent as well as the thickness of the agar into which the antibacterial agent will diffuse. All these must be put into consideration when using any antibacterial evaluation method based on diffusion. Agar diffusion method was initially designed to monitor the quantity of antimicrobial substances in crude extracts (Rios et al., 1988). There are various modifications of the technique with the same principle, which involves bringing into contact with an inoculated medium the reservoir containing the antimicrobial sample (extract) Some of the modifications are discussed below:

\section{Well diffusion assay}

Here, nutrient agar medium is seeded with specified inoculum size, poured into a sterile Petri dish and allowed to cool. With the aid of a sterile cork-borer of known diameter, a number of wells corresponding to the number of concentrations of extract to be tested are made, and a specified volume of each concentration is put inside each well, and then allowed to diffuse for at least one hour before being incubated at $37{ }^{\circ} \mathrm{C}$ for 24 hours. After incubation, the plate is observed for the presence of a zone of inhibition, which can then be measured (Figure 1). It is a usual practice to compare inhibition zones with those of antibiotics. With this practice, the antibiotic is serving only as positive control aimed at establishing the sensitivity of the test organism but not to draw relativity of antimicrobial potency between the antimicrobial samples and antibiotics (Janssen et al., 1987). It is also a common practice by some researchers to relate MIC values with inhibition diameters (Ayafor et al., 1982), but there is no relationship between the two. A WHO committee of experts recommends the application of regression lines that relate inhibition zones and MIC (Ericsson and Sherris, 1971)

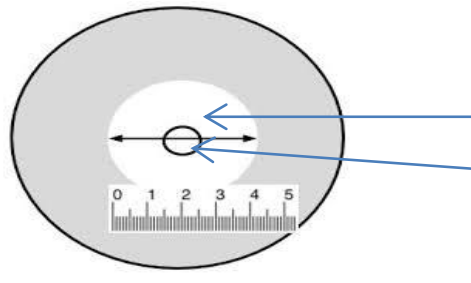

Zone of inhibition

Cup made through cork-borer in which adequate volume of agent being evaluated is put

Figure 1 Plate showing a zone of inhibition

To obtain the regression line, zones of inhibition are plotted against the logarithm of concentrations and the MIC is derived from the straight line obtained by extrapolating to a point equivalent to the diameter of the cup. The antilog of the corresponding concentration obtained is MIC (Figure 2).

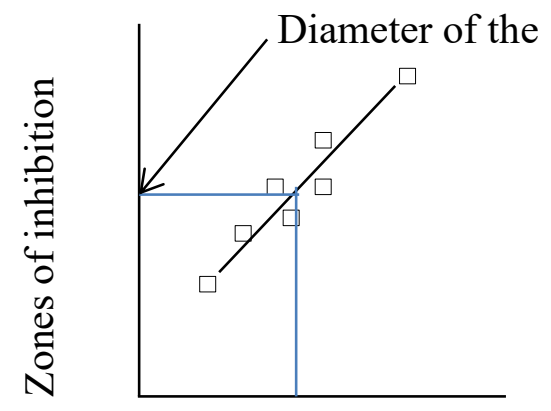

\section{Logarithm of}

Figure 2 A typical graph of zones of inhibition versus logarithm of concentrations

\section{Ditch Method}

In this method, a melted nutrient agar medium is poured into a sterile Petri dish and allowed to set. With the aid of a sterile scalpel, a ditch is made at the centre of the plate to accommodate the extract of the required concentration. From the ditch, however, bacteria to be used are streaked with the aid of sterile loop to the periphery of the plate. The plate is incubated at $37{ }^{\circ} \mathrm{C}$ for 24 hours and then examined for the presence of inhibition (Figure 3). This method has been described as being qualitative as the minimum inhibitory concentration cannot be quantified. The closer to the ditch the growth of the test organism, the less susceptible the organism is to the antibacterial effect of the extract.

The alternative to this method is "Agar plug method" in which the antibacterial agent is added to molten Agar, and the molten Agar containing antibacterial agent is used to seal the ditch and allowed to solidify. The antibacterial agent diffuses from the plug into the surrounding agar where its effect is expressed by the appearance of inhibiting zones against the test bacteria. 


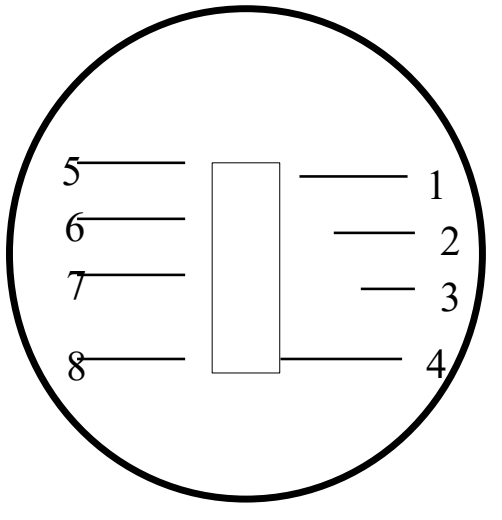

Figure 3 Plate showing a ditch containing antibacterial agent and bacteria showing varying susceptibilities to antibacterial agent after incubation. Isolate 3 is the most susceptible. Isolate 4 is not susceptible to the agent (no inhibition). Isolates $5-8$ are equally susceptible to the agent.

\section{Wedge method}

This is also known as the gradient method. $20 \mathrm{~mL}$ nutrient agar is divided into two equal parts of $10 \mathrm{~mL}$. To the first portion is added the extract to be evaluated, poured into a sterile Petri dish and allowed to set in the form of a slope by raising the plate slightly. The other portion, devoid of the extract, is poured and allowed to set with plate lying flat on the bench.

The bacteria whose susceptibility is to be determined are then streaked on the agar followed by incubation at $37{ }^{\circ} \mathrm{C}$ for 24 hours after which the plate is examined for growth inhibition (Figure 4).

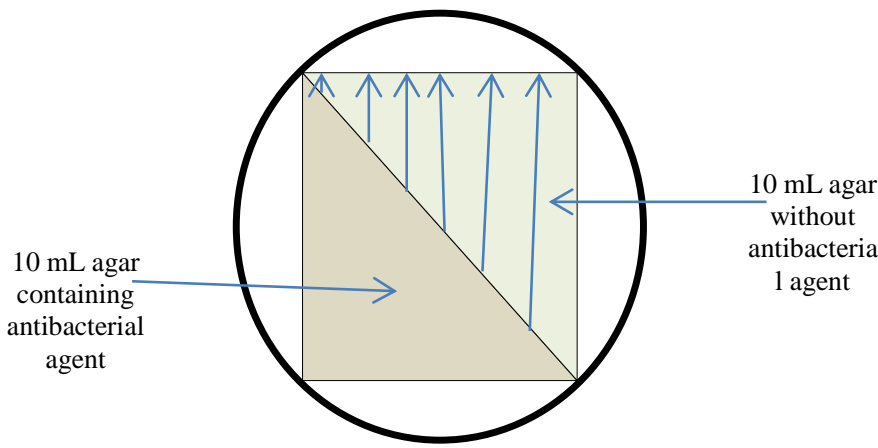

Figure 4 Plate showing area containing antibacterial agent and area without antibacterial agent. The vertical lines indicate the distance travelled by the molecules of antibacterial agent to the surface.

The direction of streaking should be such that the highest population of bacteria is deposited where the antibacterial agent travels the shortest distance.

The MIC can be calculated as:

\section{length of growth $\quad \mathrm{X}$ concentration $(\mathrm{mg} / \mathrm{mL})$ \\ length of possible growth}

The concentration has to be expressed as a function of the total volume of nutrient agar medium used $(20 \mathrm{~mL})$. This method, because it gives an idea about the possible value of the minimum inhibitory concentration, has been described as being both qualitative and quantitative.

While more than one organism but one concentration can be used for both ditch and wedge methods of evaluation, only an organism can be used for cup method but with more than one concentration of the antibacterial agent. Another advantage of the cup method is the small size of the sample used for screening. Although diffusion techniques can be used for antimicrobial screening and are well-suited for preliminary screening of pure substances (alkaloids, flavonoids, terpenoids), the methods can, however, never be used as a definitive method. Moreover, the methods should not be employed when the sample is lipophilic (not highly soluble in water). Where and when possible, the use of cup method (diffusion methods) to determine MIC should be discouraged.

Nonetheless, for optimum activity, standard conditions that have been established involve the use of Mueller-Hinton agar and standard microorganisms (ATCC or similar). Isolated pathogenic microorganisms should never be used and the results expressed by + (growth) or - (inhibition). The results can then be compared with dilution methods (Bauer et al., 1966; Mitscher et al., 1972 WHO, 1977)

\section{Dilution Method}

This includes dilution in a liquid medium and a solid medium. Both dilution methods are based on the homogeneous dispersion of the sample in a microorganism-selective culture medium. These methods are the best when it is necessary to assay water-soluble or lipophilic samples and to determine the MIC of compounds (Clark et al., 1981, 1984; Miski et al., 1983; El-Feraly et al., 1983; Adeoye et al., 1986). Dilution in the liquid medium is referred to as broth dilution method while dilution in the solid medium is called an agar dilution method. Both are discussed below.

\section{Broth Dilution Test}

This method can be macro dilution or micro dilution. Macro dilution involves preparation of graded concentrations, usually twofold dilutions, of the extract in test tubes using a suitable medium such as Mueller-Hinton broth and inoculating the concentrations with a fixed volume of the test organism. The volume of the agent in each tube ranges from $2-5 \mathrm{~mL}$. The tubes are then incubated at $37^{\circ} \mathrm{C}$ for 24 hours after which the tubes are examined for growth. The minimum concentration showing no visible growth of the test organism is taken as the MIC. Micro dilution, on the other hand, involves the use of a microtitre plate, usually 96 wells type (Figure 5). The final inoculum size in each well should be $5 \times 10^{5}$ $\mathrm{CFU} / \mathrm{mL}$. To achieve this inoculum size involves that the maximum volume of Mueller-Hinton broth in each well is $100 \mu \mathrm{L}$ to which $10 \mu \mathrm{L}$ of 1 in 20 diluted $0.5 \mathrm{McF}$ arland standard bacterial culture is added (CLSI, 2016). Usually, ten of the twelve wells are used for dilutions. The remaining two wells serve as viability control (broth + bacterial cells) and aseptic control (broth only) respectively. Since turbidity is the parameter used here, it is, therefore, crucial that the extract to be evaluated be such that will not mask the presence of turbidity. If the extract will mask turbidity, the use of dye such as resazurin and MTT to distinguish between dead and living cells is advocated apart from the use of other methods of evaluation.

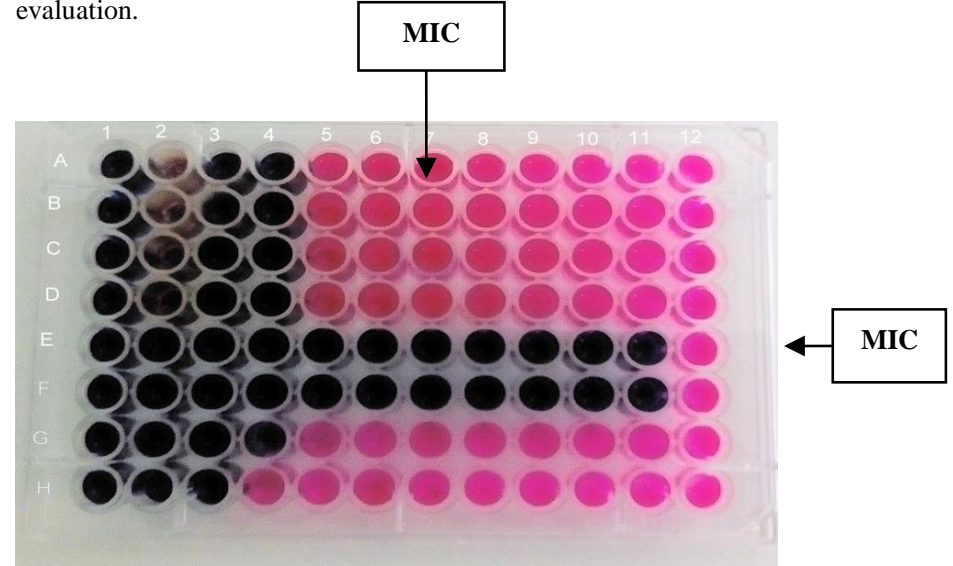

Figure 5 A microtiter plate showing minimum inhibitory concentration (MIC) following addition of $0.02 \%$ rezasurin. Wells with blue colour indicate no growth, wells with pink colour indicate bacterial growth.

\section{Agar Dilution Method}

This is similar to the broth dilution test in principle but uses solid medium instead of liquid medium and applies to both polar and non-polar samples. This method is advocated when the extract will mask the turbidity utilized to interpret the broth dilution test. It involves mixing a fixed amount of an antimicrobial agentcontaining mixture with nutrient agar and allowed to set. Test bacteria can then be streaked, or $1-10 \mu \mathrm{L}$ of the test bacteria can be dropped on the agar and the plate incubated for $18-24 \mathrm{~h}$. The final inoculum size to be used is $5 \times 10^{4}$ CFU/mL (CLSI, 2016). If the concentration of the antimicrobial agent in the agar is enough to inhibit the bacteria, the bacteria will not grow following incubation. It is to be noted that the final concentration of the agent is expressed using the total volume of the agar. For example, if $20 \mathrm{~mL}$ nutrient agar contains $100 \mu \mathrm{L}$ of $1 \mathrm{mg} / \mathrm{mL}$ stock solution of the extract, the concentration of the agent tested will be $5 \mu \mathrm{g} / \mathrm{mL}$. Where and when many organisms are to be screened, a multiplepoint inoculator can be used, and the minimum concentration that inhibits the growth of the test organism is taken as the MIC.

Agar dilution method is advantageous because of its simplicity, rapidity and possibility of its use in the antimicrobial evaluation of water-soluble or insoluble samples such as essential oils. It also allows for the usage of more than one organism at a time.

\section{Dilution versus Diffusion}

It is essential that the method used, and conditions are clearly stated in all antimicrobial studies. This is necessary to ensure reproducibility of the results of the work. The same antimicrobial agent can give different effect against the 
same organism using different antimicrobial assay methods. For instance, Pellecuer et al. (1976) reported different results for phenol and essential oil of Thymus against Escherichia coli using dilution and diffusion methods. The activity of the two agents was the same when diffusion (disks) method was used with phenol producing a zone of inhibition having $42 \mathrm{~mm}$ in diameter and the essential oil with $41 \mathrm{~mm}$ zone of inhibition. However, the dilution method revealed essential oil to be more active (1/3000) than the phenol (1/1000). Contradictory results were obtained when the authors compared the activity of the essential oil against two different microorganisms Escherichia coli and Staphylococcus aureus with the essential oil more active against $S$. aureus by the disk diffusion method and $E$. coli being more sensitive when they used the liquid dilution method. Similarly, Yousef and Tawil (1980) obtained and reported contradictory results in the study of 22 essential oils when they used hole-plate diffusion or the liquid dilution method.

All the fractions of Helinus integrifolius showed activity against Candida albicans when the liquid dilution method was used, but none of the fractions showed activity using the cup-plate diffusion method (Gundiza, 1987). The reason has been attributed to plant extracts having low diffusion properties unlike in dilution method where the extracts are in direct contact with the test organism, even with low solubility in water of the extracts. Extracts with low solubility tend to sediment during incubation and to avoid this, shaking during incubation is advocated. Also, extracts displaying low solubility can be emulsified with a suitable surface-active-agent such as Tween 20 or Tween 80 at an idea percentage of $10 \%$ without having their activity impaired or modified. Although the percentage of the surface active agent used may vary depending on the sample, what is, however, important is that the stability of the formed emulsion must remain constant throughout the assay period.

Nonetheless, similar results have been obtained using both the agar dilution and microdilution method. For instance, the results of the MICs obtained during the evaluation of the susceptibility of 110 anaerobic bacteria to some widely used antibiotics (chloramphenicol, penicillin, clindamycin) using the agar dilution and micro-broth dilution method were similar (Baron and Bruckner, 1984) Similarly, the susceptibility of 200 strains of Pseudomonas aeruginosa isolated from hospitalized patients to antibiotics using both agar dilution and microdilution methods showed similar results (Gabrielyan et al., 1985).

The solution to what constitutes an acceptable quantity of extract required for activity has been provided by Mitscher et al. (1987). According to these authors, if a pure substance is not active at $100 \mu \mathrm{g} / \mathrm{mL}$, it probably will not be clinically useful. Plant extracts that are active at a concentration of $100 \mu \mathrm{g} / \mathrm{mL}$ have a good potency level and, depending upon the general chemical nature of the componen responsible for the activity; a subsequent purification technique can be decided upon.

\section{Bioautography}

This has been used to identify new or unknown compounds using either paper chromatography or thin layer chromatography (TLC). However, TLC has enjoyed more acceptability over paper chromatography because of the higher resolving power as well as being more rapid than the paper chromatography. TLC is often utilized to separate complex mixtures based on the balance of hydrophilic, hydrophobic and steric interactions as well as hydrogen bonding, occurring between the analytes and the mobile and stationary phases (Cid

Hernandez et al., 2018). The separation of a mixture into its components often generates a chromatogram, as shown in Figure 6.

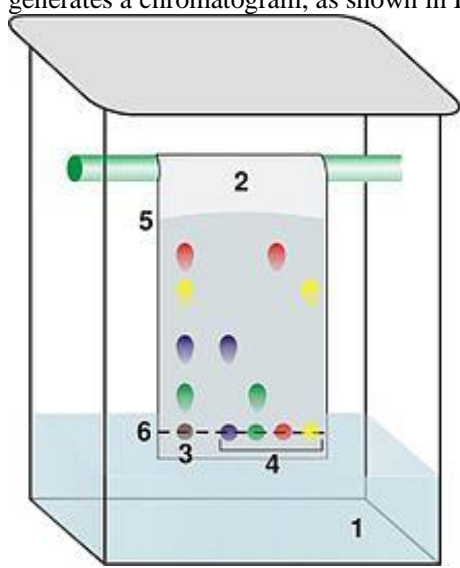

Figure 6 A chromatogram of a Thin Layer Chromatography (TLC).

(1: solvent; 2: TLC plate; 3: reference spot; 4: test mixture spots; 5: solvent front; 6: origin/baseline)

Rate of flow (Rf) of each component can thus be calculated as: $\mathrm{Rf}=$ Distance moved by the component from the origin (baseline spot) Distance moved by the solvent front from the origin
It is to be noted that the $\mathrm{Rf}$ value is always constant under fixed conditions as TLC plate, developing solvent, and temperature. Thus, each compound can be identified based on the Rf value along with the shape and color of its spot.

TLC can be a one- or a two- dimensional. A one-dimensional (1D) TLC is usually done in one direction using a polar solvent while a two-dimensional (2D) TLC is done in two directions perpendicular to each other using a polar and a non-polar solvent respectively (Wedge and Nagle, 2000). Zarzycki et al. (2011) applied a one-dimensional TLC technique (1D-TLC) to separate the chemical components present in four pharmaceutical formulations of Spirulina platensis while Cid-Hernandez et al. (2018) designed a two-dimensional TLC bioautography to separate and locate metabolites with antioxidant activity contained in Spirulina platensis. Similarly, Wedge and Nagle (2000) used a 2DTLC bioautography method for the discovery of novel antifungal agents to control plant pathogens. Bioautography can be classified into the agar diffusion method, direct contact method and agar overlay method.

\section{Agar contact technique}

The agar diffusion method is also known as agar contact technique. Here, the chromatogram of the crude extract to be tested is made either on paper or glass. The chromatoplaque is then allowed to make contact with the surface of solidified agar that has been seeded with the test bacteria for some minutes or hours to allow for diffusion of the antibacterial agent from the chromatogram into the agar. The chromatogram is removed, and the agar plate is then incubated. There is growth inhibition on the agar plate, which corresponds to the component of the chromatogram having antibacterial activity.

\section{Direct contact technique}

Direct contact technique involves dipping in or spraying the chromatogram plate with the bacterial suspension and incubating the plate at $25{ }^{\circ} \mathrm{C}$ for 48 hours under humid condition (Dewanjee et al., 2015). This is the most applied of all the three bioautography methods and can be used with either bacteria or fungi. Following incubation, visualization of microbial growth can be done by spraying the chromatoplaque with tetrazonium salts and the plaque re-incubated at $25{ }^{\circ} \mathrm{C}$ for 24 hours (for fungi) (Silva et al., 2005) or $3-4$ hours at $37^{\circ} \mathrm{C}$ (for bacteria) (Runyoro et al., 2006) during when there is colour formation due to conversion of tetrazonium salt to intensely coloured Formazan by dehydrogenases of living cells. Consistent results have been reported with spore-producing fungi such as Aspergillus, Penicillium and Cladosporium (Suleiman et al., 2010) while Bacillus subtilis, Staphylococcus aureus and Escherichia coli strains are frequently used to identify antibacterial compounds (Hamburger and Cordell, 1987; Horvath et al., 2010)

\section{Agar overlay technique}

In this method, molten agar is seeded with a suspension of the test organism and then poured on the TLC plate of the test compounds. The plate can be left for some time at low temperature to allow for diffusion of the antimicrobial agent from the chromatogram into the agar after which the plate is incubated at appropriate temperature and time depending on the test organism. Following incubation, the plate is then sprayed with tetrazonium salts and re-incubated to allow for visualization (Balouiri et al., 2016).

In general, apart from localizing the active component of the test compound, TLC-bioautography is a simple, effective, inexpensive and rapid technique for the screening of a large number of samples for bioactivity and in the bioactivityguided fractionation. TLC-bioautography can also be used for the detection of antimicrobials in environmental and food samples as well as for searching for new antimicrobial drugs.

\section{Determination of Bactericidal activity}

Bactericidal activity of antibacterial agents can be evaluated against different bacterial isolates using various in vitro microbiological techniques such as the minimum bactericidal concentration (MBC), time-kill curve and serum bactericidal titer (SBT). Each technique may provide useful information, but clinical values of these techniques are limited by technical problems and difficulty in practical interpretation (Peterson and Shanholtzer, 1992; Vosti, 1989; Washington, 1992).

\section{MBC determination}

The Minimum Bactericidal Concentration (MBC) can be determined from broth microdilution or macro-dilution method by sub-culturing from those tubes (macro- dilution) or wells (micro-dilution) showing no turbidity (blue wells) into recovery medium and incubate accordingly at the appropriate temperature for appropriate period of time after which the medium will be examined for the presence or otherwise of growth (Figure 6) (CLSI, 1999). 


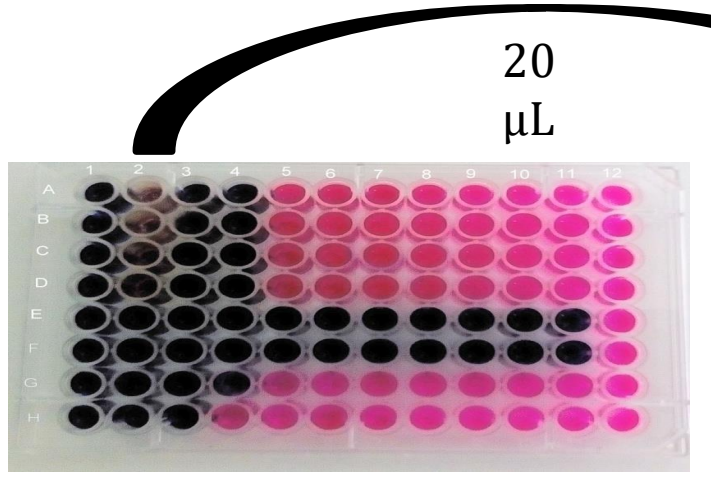

96 - well plate showing growth inhibition of the planktonic cells of bacteria by antimicrobial.

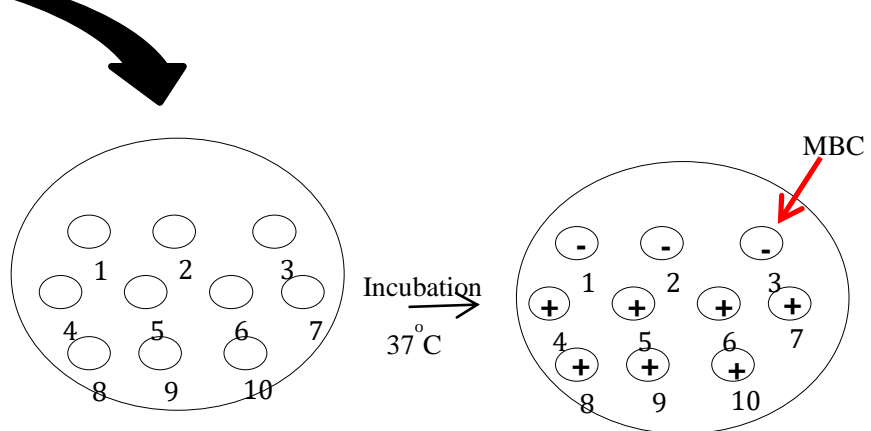

Plate of Mueller-Hinton agar
Plate of Mueller-Hinton

agar showing bacterial growth

Figure 7 Determination of minimum bactericidal concentration from micro-dilution wells

Recovery medium may be broth or solid agar devoid of antimicrobial agent and will support the growth of the test organism. A selective or diagnostic medium should not be used for this purpose, but rather a general purpose medium should be used. Minimum concentration from the tubes/wells showing no turbidity in which there is no growth after sub-culturing is taken as the MBC. It is worthy of note that it is possible for both MIC and MBC to be incorporated in only one concentration. With this, it is likely that the agent lacks inhibitory activity or that the difference between the MIC and MBC is so close which can be likened to a chemotherapeutic agent with a narrow therapeutic window.

\section{Time-Kill method}

This method is used to evaluate the rate of killing of bacteria by an antibacterial agent. It involves challenging a known concentration of an antibacterial agent with a fixed bacterial inoculum, and at a regular interval, a sample is withdrawn onto a nutrient agar medium, incubated at $37{ }^{\circ} \mathrm{C}$ for 24 hours and number of survivors determined by counting the colonies on the medium after incubation. The volume of the sample withdrawn is usually replaced with an equal volume of the antibacterial agent at the concentration being tested after each withdrawal. A straight line graph can be generated by plotting the logarithm of the number of the survivor on the ordinate against the time/concentration on the abscissa from where the number of organisms killed per unit time or unit concentration by the extract can be determined from the slope (Figure 7). Time-kill curves have been utilised to determine the kinetics of bacterial killings in vitro, but have not been used routinely to determine whether an antibacterial agent is bacteriostatic or bactericidal. They can, however, be useful in distinguishing whether bacterial killing is concentration and/or time-dependent. Concentration-dependen bacterial killing takes place when the rate and extent of bacterial killing increases with proportionally higher antibacterial concentration and time-dependent killing occurs when increasing antibacterial concentration to more than the MIC do not result in a proportional increase in killing (Pankey and Sabath, 2004). Another advantage of this method is that it is one of the most reliable means of determining tolerance (Tuomanen, 1986; Tuomanen et al., 1986). It can also be used to determine synergy or antagonism between two (or more) antimicrobial agents (King et al., 1981; Chalkley and Koornhoff, 1985).

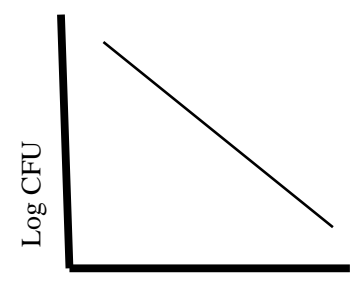

$\mathrm{Ti}$

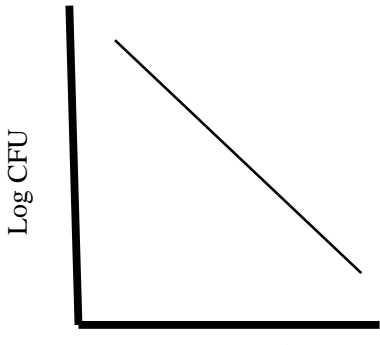

Concentration
I

Figure 8 Plot of $\log$ colony forming unit (CFU) against (I) time (Timedependent) and (II) concentration (Concentration-dependent).

Over time, colony counts may increase after an initial decrease. This can be due to the selection of resistant mutants, inactivation of the antimicrobial agent, or regrowth of susceptible bacterial cells which have escaped the antimicrobial activity by adhering to the wall of the culture vessel (Taylor et al., 1983; Gwynn et al., 1981; Layte et al., 1983).
In summary, MIC and MBC values depict the outcome of an in vitro test in which a fixed concentration of an antibacterial agent is being evaluated against an initially fixed concentration of bacteria in an aqueous medium. The in vitro result does not usually correspond with the in vivo situation, in which antibacterial and bacterial concentrations in different body fluids and tissues may fluctuate widely (Estes, 1998; Volgeman and Craig, 1986).

\section{CONCLUSION}

Medicinal plants are everywhere and are easily accessible. Their antimicrobial activity can be optimized and reproduced by collecting the correct species of the medicinal plant, using the correct method of extraction and complying with the provisions of correct microbiological screening principles. Failure of any of these provisions may lead to non-reproducibility of the claimed and reported antimicrobial activity of many potent, efficacious and promising medicinal plants that can lead to the discovery of novel antimicrobials especially now that incidence of resistance to conventional antibiotics is on the increase.

\section{REFERENCES}

Adeoye, A. D., Oguntimein, B. O., Clark, A. M. 1986. 3-Dimethylallylindone: an antibacterial and antifungal metabolite from Monodora tenuifolia. J. Nat. Prod. 49(3), 534-537. http://dx.doi.org/10.1021/np50045a031

Akinyemi, K. O., Oladapo, O., Okwara, C. E., Ibe, C. C., Fasure, K. A. 2005 Screening of crude extracts of six medicinal plants used in South-West Nigerian unorthodox medicine for anti-methicillin resistant Staphylococcus aureus activity. BMC Complement Altern Med., 5, 6. http://dx.doi.org/10.1186/14726882-5-6

Amaechina, O. O. (2003). Three - minute Herbal Treatment to reduce dental caries with a Newbouldia laevis based extract. Am. J. Undergrad. Res., 2(2), 1 4.

Ankanna, S., Suhrulatha, D., Savithramma, N. 2012. Chemotaxonomical studies of some important monocotyledons. Botany Research International, 5(4), 90-96 http://dx.doi.org/10.5829/idosi.bri.2012.5.4.501

Audu, S. A., Mohammed, I., Kaita, H. A. 2007. Phytochemical screening of the leaves of Lophira lanceolata (Ochanaceae). Life Science Journal, 4(4), 75-79.

Ayafor, J. F., Sondengam, B. L., Ngadjui, B. T. 1982. Veprisinium salt, a novel antibacterial quaternary alkaloid from Vepria lorisii. Planta Medica, 44(03), 139142. http://dx.doi.org/ 10.1055/s-2007-971423

Balouiri, M., Sadiki, M., Ibnsouda, S. K. 2016. Methods for in vitro evaluating antimicrobial activity: A review. J. Pharm. Anal., 6(2), 71-79. http://dx.doi.org/10.1016/j.jpha.2015.11.005

Banso, A., Adeyemo, S. O. 2007. Evaluation of antibacterial properties of tannins isolated from Dichrostachys cinerea. Afr. J. Biotechnol., 6(15), 1785 - 1787.

Baron, E. J., Bruckner, D. A. 1984. Comparison of susceptibilities of anaerobic bacteria determined by agar dilution and by a microbroth method. Rev Infect Dis. 1, 249-253

Bauer, A. W., Kirby, W. M. M., Sherris, J. C., Turck, M. 1966. Antibiotic susceptibility testing by a standardized single disk method. Am J Clin Pathol., 45(4), 493-496

Beckonert, O., Keun, H. C., Ebbels, T. M., Bundy, J., Holmes, E., Lindon, J. C., Nicholson, J. K. 2007. Metabolic profiling, metabolomic and metabonomic procedures for NMR spectroscopy of urine, plasma, serum and tissue extracts Nat Protoc, 2(11), 2692-703. http://dx.doi.org/10.1038/nprot.2007.376

Ben, I. O., Woode, E., Abotsi, W. K. M. Boakye-Gyasi, E. 2013. Preliminary phytochemical screening and in vitro antioxidant properties of Trichilia monadelpha (Thonn.) J. J. de Wilde (Meliaceae). Journal of Medical and Biomedical Sciences, 2(2): 6-15.

Bernini, P., Bertini, I., Luchinat, C., Nincheri, P., Staderini, S., Turano, P. 2011 Standard operating procedures for pre-analytical handling of blood and urine for 
metabolomic studies and biobanks. $J$ Biomol NMR, 49(3-4), 231-43. http://dx.doi.org/10.1007/s10858-011-9489-1.

Bhargava, V. V., Patel, S. C., Desai, K. S. 2013. Importance of terpenoids and essential oils in chemotaxonomic approach. Int. J. Herb. Med., 1(2), 14-21.

Bhatnagar, B. S., Bogner, R. H., Pikal, M. J. 2007. Protein stability during freezing: separation of stresses and mechanisms of protein stabilization. Pharm Dev Technol, 12(5), 505-23. http://dx.doi.org/10.1080/10837450701481157

Broadhurst, D. I., Kell, D. B. 2006. Statistical strategies for avoiding false discoveries in metabolomics and related experiments. Metabolomics, 2(4), 171 96. http://dx.doi.org/10.1007/s11306-006-0037-z

Cid-Hernández, M., Dellamary-Toral, F. A. L., González-Ortiz, L. J., SánchezPeña, M. J., Pacheco-Moisés, F. P. 2018. Two-dimensional thin laye chromatography-bioautography designed to separate and locate metabolites with antioxidant activity contained on Spirulina platensis. Int J Anal Chem 2018:4605373. http://dx.doi.org/10.1155/2018/4605373

Chalkley, L. J., Koornhoff, H. J. 1985. Antimicrobial activity of ciprofloxacin against Pseudomonas aeruginosa, Escherichia coli, and Staphylococcus aureus determined by the killing curve method: Antibiotic comparisons and synergistic interactions. Antimicrob Agents Chemother, 28(2), 331-342. http://dx.doi.org/10.1128/AAC.28.2.331

Clark, A. M., El-Feraly, F. S., Li, W. S. 1981. Antimicrobial activity of phenolic constituents of Magnolia grandiflora L. J. Pharm. Sci, 70(8), 951- 952. http://dx.doi.org/10.1002/jps.2600700833

Clark, A. M., Huddleston, D. L., Ma, C. Y., Ho, C. H. 1984. In vitro antimicrobial activity of benzoquinolinediones. Pharm Res, 1(6), 289-271. http://dx.doi.org/10.1023/A:1016398003032

Clinical and Laboratory Standards Institute. 1999. Methods for Determining Bactericidal Activity of Antimicrobial Agents; Approved Guideline. CLSI; 19(18)

Clinical and Laboratory Standards Institute (CLSI). Performance standards for antimicrobial susceptibility testing, M100-S26. Twenty-Fourth Informationa Supplement. Clinical and Laboratory Standards Institute, Wayne, PA, 2016

Cowan, M. M. 1999. Plant products as antimicrobial agents. Clin Microbiol Rev, 12(4), 564-82

Cuhadar, S., Koseoglu, M., Atay, A., Dirican, A. 2013. The effect of storage time and freeze-thaw cycles on the stability of serum samples. Biochem Med (Zagreb), 23(1), 70-7. http://dx.doi.org/10.11613/BM.2013.009

Damintoti, K., Aly, S., Antonella, C., Saydou, Y., Carla, M., Jacques, S., Vittorio, C., Alfred, A. S. 2005. Antibacterial activity of alkaloids from Sida acuta. Afr. J. Biotechnol., 5(2), 195 - 200.

Das, K., Tiwari, R. K. S., Shrivastara, D. K. 2010. Techniques for evaluation of medicinal plants products as antimicrobial agent: current methods, and future trends. J. Med. Plants Res., 4(2), 104 http://dx.doi.org/10.5897/JMPR09.030

Denyer, S. P., Stewart, G. S. A. B. 1998. Mechanisms of action of disinfectants. $\begin{array}{lll}\text { Int Biodeterior Biodegradation, 41(3-4), 261-268. } & \end{array}$ http://dx.doi.org/10.1016/S0964-8305(98)00023-7

Dewanjee, S., Gangopadhyay, M., Bhattabharya, N., Khanra, R., Dua, T. K 2015. Bioautography and its scope in the field of natural product chemistry. $J$. Pharm. Anal., 5(2), 75-84. http://dx.doi.org/10.1016/j.jpha.2014.06.002

Draper, J., Enot, D. P., Parker, D., Beckmann, M., Snowdon, S., Lin, W., Zubair H. 2009. Metabolite signal identification in accurate mass metabolomics data with $\mathrm{MZedDB}$, an interactive $\mathrm{m} / \mathrm{z}$ annotation tool utilising predicted ionisation $\begin{array}{llll}\text { behaviour "rules". BMC Bioinformatics, } & 10, & 227 .\end{array}$ http://dx.doi.org/10.1186/1471-2105-10-227

Dunn, W. B., Erban, A., Weber, R. J., Creek, D. J., Brown, M., Breitling, R., Hankemeier, T., Goodacre, R., Neumann, S., Kopka, J., Viant, M. R. 2013. Mass appeal: metabolite identification in mass spectrometry-focused untargeted metabolomics. Metabolomics, 9(1), 44-66. http://dx.doi.org/10.1007/s11306012-0434-4

Dunn, W. B., Wilson, I. D., Nicholls, A. W., Broadhurst, D. 2012. The importance of experimental design and QC samples in large-scale and MS-driven untargeted metabolomic studies of humans. Bioanalysis, 4(18), 2249-64 http://dx.doi.org/10.4155/bio.12.204

El-Feraly, F. S., Cheatham, S. F., Breedlove, R. L. 1983. Antimicrobial neolignans of Sassafras randaiense roots. J. Nat. Prod., 46(4), 493-498. http://dx.doi.org/10.1021/np50028a012

Eloff, J. N. 1998. Which extractant should be used for the screening and isolation of antimicrobial components from plants. J. Ethnopharmacol., 60(1), $1-8$ http://dx.doi.org/10.1016/S0378-8741(97)00123-2

Elrod, S. L., Stansfield, W. D. 2002. Theory and Problems of Genetics. New Delhi: McGraw-Hill, 445p, ISBN 0 - 0 7 - 060877 - 6 .

Emwas, A. H., Luchinat, C., Turano, P., Tenori, L., Roy, R., Salek, R. M., Ryan, D., Merzaban, J. S., Kaddurah-Daouk, R., Zeri, A. C., Gowda, G. A. N., Raftery, D., Wang, Y., Brennan, L., Wishart, D. S. 2015. Standardizing the experimental conditions for using urine in NMR-based metabolomic studies with a particular focus on diagnostic studies: a review. Metabolomics, 11(4), 872-94. http://dx.doi.org/10.1007/s11306-014-0746-7
Ericsson, H. M., Sherris, J. C. 1971. International collaborative study on antibiotic sensitivity testing. Acta Pathol Microbiol Scand B Microbiol Immunol, 217, 3-88.

Estes, L. 1998. Review of pharmacokinetics and pharmacodynamics of antibacterial agents. Mayo Clin. Proc., 73(11), $1114-22$ http://dx.doi.org/10.4065/73.11.1114

Evans, W. C. 2008. Trease and Evans' Pharmacognosy. London: WB Saunders, 616p, ISBN: 978-0-7020-2933-2.

Farnsworth, N. R. 1966. Biological and Phytochemical screening of plants. $J$. Pharm. Sci., 55(3), 225 - 276. https://doi.org/10.1002/jps.2600550302

Fiehn, O. 2002. Metabolomics-the link between genotypes and phenotypes. Plant Mol Biol, 48(1-2), 155-71. http://dx.doi.org/10.1023/A:1013713905833

Gabrielyan, S. A., Bogdanova, L. F., Vorob'eva, L. S., Givental, N. I. 1985 Comparative estimation of agar dilution and agar diffusion methods in determination of Pseudomonas aeruginosa sensitivity to certain antibiotics. Antibiot Med Biotekhnol, 30(7), 511- 516.

Gika, H. G., Theodoridis, G. A., Wilson, I. D. 2008. Liquid chromatography and ultra-performance liquid chromatography-mass spectrometry fingerprinting of human urine: sample stability under different handling and storage conditions for metabonomics studies. $J$ Chromatogr A, 1189(1-2), 314-22. http://dx.doi.org/10.1016/j.chroma.2007.10.066

Gika, H. G., Theodoridis, G. A., Wingate, J. E., Wilson, I. D. 2007. Within-day reproducibility of an HPLC-MS-based method for metabonomic analysis: application to human urine. J Proteome Res, 6(8), 3291-303. http://dx.doi.org/10.1021/pr070183p

Gowda, G. N., Zhang, S., Gu, H., Asiago, V., Shanaiah, N., Raftery, D. 2008 Metabolomics-based methods for early disease diagnostics. Expert Rev Mol Diagn, 8(5), 617-33. http://dx.doi.org/10.1586/14737159.8.5.617

Gundidza, M. 1987. Antimicrobial activities of Helinus integrifolius. Fitoterapia 58(3), 180- 183

Gwynn, M. N., Webb, L. T., Rolinson, G. N. 1981. Regrowth of Pseudomonas aeruginosa and other bacteria after the bactericidal action of carbenicillin and other beta-lactam antibiotics. $J$ Infect Dis., 144(3), 263-269. http://dx.doi.org/10.1093/infdis/144.3.263

Hamburger, M. O., Cordell, G. A. 1987. A direct bioautographic TLC assay for compounds possessing antibacterial activity. J. Nat. Prod., 50(1), 19-22 http://dx.doi.org/10.1021/np50049a003

Hocking, G. M. 1977. The Doctrine of Signatures. Quart. J. Crude Drug Res., 15(4), 198-200. http://dx.doi.org/10.3109/13880207709055172

Horváth, G., Jámbor, N., Végh, A., Boszormenyi, A., Lemberkovics, E. Hethelyi, E., Kovacs, K., Kocsis, B. 2010. Antimicrobial activity of essential oils: the possibilities of TLC-bioautography. Flavour Fragr. J., 25(3), 178-182. http://dx.doi.org/10.1002/ffj.1993

Ioannidis, J. P., Khoury, M. J. 2011. Improving validation practices in “omics' research. Science, 334(6060), 1230-2. http://dx.doi.org/10.1126/science.1211811.

Janssen, M., Scheffer, J. J. C., Svendsen, A. B. 1987. Antimicrobial activity of essential oils: a 1976-1986 literature review. Aspects of the test methods. Planta Med, 53(5), 395-398. http://dx.doi.org/10.1055/s-2006-962755

Khafagi, I. K., Dewedar, A. 2000. The efficiency of random versus ethnodirected research in evaluation of Sinai Medicinal plants for bioactive compounds. $J$. Ethnopharmacol, 71(3), 365 - 376. http://dx.doi.org/10.1016/S03788741(00)00164-1

King, T. C., Schlessinger, D., Krogstad, D. J. 1981. The assessment of antimicrobial combinations. Rev Infect Dis, 3(3), 627-633. http://dx.doi.org/10.1093/clinids/3.3.627

Lamikanra, A. (1999). Essential Microbiology for students and Practitioners of Pharmacy, Medicine and Microbiology. Lagos: AMKRA.

Layte, S., Harris, P., Rolinson, G. N. 1983. Factors affecting the apparen regrowth of Pseudomonas aeruginosa following exposure to bactericidal concentrations of carbenicillin. Chemotherapy, 30(1), 26-30. http://dx.doi.org/10.1159/000238240

Leung, T. F., Ko, F. W., Wong, G. W. 2013. Recent advances in asthma biomarker research. Ther Adv Respir Dis, 7(5), 297-308 http://dx.doi.org/10.1177/1753465813496863

Li, Y., Guo, C., Yang, J., Wei, J., Xu, J., Cheng, S. 2006. Evaluation of antioxidant properties of pomegranate peel extract in comparison with pomegranate pulp extract.Food Chem, 96(2), 254-260 http://dx.doi.org/10.1016/j.foodchem.2005.02.033

Mattila, P., Kumpulainen, J. 2002. Determination of free and total phenolic acids in plant-derived foods by HPLC with Diode-Array detection. J. Agric. Food Chem., 50(13), 3660-3667. http://dx.doi.org/10.1021/jf020028p

McDonnell, G., Russell, A. D. 1999. Antiseptics and disinfectants: activity, action, and resistance. Clin Microbiol Rev, 12(1), 147-179.

Meyer, B., Cookson, B. 2010. Does microbial resistance or adaptation to biocides create a hazard in infection prevention and control? J Hosp Infect, 76(3), 200 205. http://dx.doi.org/10.1016/j.jhin.2010.05.020

Middleton, E., Kandaswami, C. 1994. The impact of plant flavonoids on mammalian biology: implications for immunity, inflammation and cancer. In The flavonoids: advances in research since 1986, Harborne J. B. (ed.), New York: 
Routledge,

$676 \mathrm{p}$

ISBN:

9780203736692 http://dx.doi.org/10.1201/9780203736692

Miski, M., Vlubelen, A., Johansson, C., Mabry, T. J. 1983. Antibacterial activity studies of flavonoids from Salvia palaestina. J Nat Prod, 46(6), 874 - 875 http://dx.doi.org/10.1021/np50030a007

Mitscher, L. A., Drake, S., Gollapudi, S. R., Okwute, K. 1987. A modern look at folkloric use of anti-infective agents. J NatProd, 50(6), 1025-1040. http://dx.doi.org/10.1021/np50054a003

Mitscher, L. A., Leu, R. P., Bathala, M. S., Wu, W. N., Beal, J. L., White, R. 1972. Antimicrobial agents from higher plants. I: Introduction, rationale and methodology. Lloydia, 35(2), 157-166

Ncube, N. S., Afolayan, A. J., Okoh, A. I. 2008. Assessment techniques of antimicrobial properties of natural compounds of plant origin: current methods and future trends. Afr. J. Biotech., 7(12), $1797-1806$

Obasi, N. L., Egbuonu, A. C. C., Ukoha, P. O., Ejikeme, P. M. 2010. Comparative phytochemical and antimicrobial screening of some solvent extracts of Samanea saman pods. African journal of pure and applied chemistry, 4(9), 206-212.

Pankey, G. A., Sabath, L. D. 2004. Clinical relevance of bacteriostatic versus bactericidal mechanisms of action in the treatment of Gram-positive bacteria infections. Clin Infect Dis, 38(6), 864 - 870. http://dx.doi.org/10.1086/381972.

Patti, G. J., Yanes, O., Siuzdak, G. 2012. Innovation: metabolomics: the apogee of the omics trilogy. Nat Rev Mol Cell Bio, 13(4), 263-9. https://doi.org/ $10.1038 / \mathrm{nrm} 3314$

Pellecuer, S., Allegrini, J., Simeon de Buochbergm, M. 1976. Huiles essentielles bactericides et fongicides. Revue de l'Institut Pasteur de Lyon, 9, 135- 159.

Peterson, L. R., Shanholtzer, C. J. 1992. Tests for bactericidal effects of antibacterial agents: Technical performance and clinical relevance. Clin Microbiol Rev, 5(4), 420 - 32 http://dx.doi.org/10.1128/CMR.5.4.420.

Rios, J. L., Recio, M. C., Villaw, A. 1988. Screening methods for natural products with antimicrobial activity: a review of the literature. $J$ Ethnopharmacol, 23(2-3), 127- 149. http://dx.doi.org/10.1016/0378 $\underline{\text { 8741(88)90001-3 }}$

Robards, K., Antolovich, M. 1997. Analytical chemistry of fruit bioflavonoids: a review. Analyst, 122(2), 11R-34R. http://dx.doi.org/10.1039/a606499j

Roberts, L. D., Souza, A. L., Gerszten, R. E., Clish, C. B. 2012. Targeted metabolomics. Curr Protoc Mol Biol, 30(2), 1-24. http://dx.doi.org/ 10.1002/0471142727.mb3002s98

Rodrigues, L., Duarte, A., Figueiredo, A. C., Brito, L., Teixeira, G., Moldao, M., Monteiro, A. 2012. Chemical composition and antibacterial activity of the essential oils from the medicinal plant Mentha cervina L. grown in Portugal. Med Chem Res, 21(11), 3485-3490. http://dx.doi.org/10.1007/s00044-011-9858-z

Roopashree, T. S., Dang, R., Rani, S. R. H., Narendra, C. 2008. Antibacteria activity of anti-psoriatic herbs: Cassia tora, Momordica charantia and Calendula officinalis. Int. J. Appl. Res. Nat. Prod., 1(3), 20-28.

Rosenling, T., Stoop, M. P., Smolinska, A., Muilwijk, B., Coulier, L., Shi, S., Dane, A., Christin, C., Suits, F., Horvatovich, P. L., Wijmenga, S. S., Buydens, L. M. C., Vreeken, R., Hankemeier, T., van Gool, A. J., Luider, T. M., Bischoff, R. 2011. The impact of delayed storage on the measured proteome and metabolome of human cerebrospinal fluid. Clin Chem, 57(12), 1703-11. http://dx.doi.org/10.1373/clinchem.2011.167601

Runyoro, D. K., Matee, M. I., Ngassapa, O. D., et al. (2006). Screening of Tanzanian medicinal plants for anti-candida activity. BMC Complement Altern Med, 6, 11. http://dx.doi.org/10.1186/1472-6882-6-11

Russell, A. D. 2002. Antibiotic and biocide resistance in bacteria: Introduction. $J$ Appl Microbiol, 92(s1), 1S-3S. $\quad$ http://dx.doi.org/10.1046/j.13652672.92.5s1.14.x

Russell, A. D., Chopra, I. 1996. Understanding Antibacterial Action and Resistance. London: Ellis Horwood, 292p, ISBN: 0-13-124827-8.

Sies, H., Schewe, T., Heiss, C., Kelm, M. 2005. Cocoa polyphenols and inflammatory mediators. Am J Clin Nutr, 81(1 suppl), 304S-12S http://dx.doi.org/10.1093/ajcn/81.1.304S

Silva, M. T. G., Simas, S. M., Batista, T. G., Cardarelli, P., Tomassini, T. C. B. 2005. Studies on antimicrobial activity, in vitro, of Physalis angulata L. (Solanaceae) fraction and Physalin B bringing out the importance of assay determination. Mem Inst Oswaldo Cruz, 100(7), 779-782. http://dx.doi.org/10.1590/s0074-02762005000700018

Singh, R. 2016. Chemotaxonomy: A Tool for Plant Classification. J. Med. Plants Stud., 4(2), 90-93.

Soetan, K. O., Oyekunle, M. A., Aiyelaagbe, O. O., Fafunso, M. A. 2006 Evaluation of the antimicrobial activity of saponins extract of Sorghum Bicolor L. Moench. Afr. J. Biotechnol., 5 (23), $2405-2407$.

Sofowora, A. 2008. Medicinal Plants and Traditional Medicine in Africa. Ibadan: Spectrum Books, 378p.

Sofowora, A., Ogunbodede, E., Onayade, A. 2013. The role and place of medicinal plants in the strategies for disease prevention. Afr J Tradit Complement Altern Med., 10(5), 210-229. http://dx.doi.org/10.4314/ajtcam.v10i5.2

Suleimana, M., McGaw, L., Naidoo, V., Eloff, J. N. 2010. Detection of antimicrobial compounds by bioautography of different extracts of leaves of selected South African tree species. Afr. J. Tradit. Complement. Altern. Med. 7(1), 64-78. http://dx.doi.org/10.4314/ajtcam.v7i1.57269

Sutcliffe, J. A., Mueller, J. P., Utt, E. A. 1999. Antibiotic Resistance Mechanisms of Bacterial Pathogens in: Manual of Industrial Microbiology and Biotechnology. A. L. Demain, J. E. Davies (Eds), Washington: ASM Press

Tanaka, J. C. A., Da Silva, C. C., De Oliveira, A. J. B., Nakamura, C. V., Dias Filho, B. P. 2006. Antibacterial activity of indole alkaloids from Aspidosperma ramiflorum. Braz. J. Med. Biol. Res., 39(3), 387 - 391. http://dx.doi.org/10.1590/S0100-879X2006000300009

Taylor, P. C. Schoenknecht, F. D. Sherris, J. C., Linner, E. C. 1983. Determination of minimal bactericidal concentrations of oxacillin for Staphylococcus aureus: influence and significance of technical factors. Antimicrob Agents Chemother, 23(1), 142-150. http://dx.doi.org/10.1128/AAC.23.1.142

Teahan, O., Gamble, S., Holmes, E., Waxman, J., Nicholson, J. K., Bevan, C., Keun, H. C. 2006. Impact of analytical bias in metabonomic studies of human blood serum and plasma. Anal Chem, 78(13), 4307-18 http://dx.doi.org/10.1021/ac051972y

Tiwari, P., Kumar, B., Kaur, M., Kaur, G., Kaur, H. 2011. Phytochemical screening and extraction: A Review. Internationale Pharmaceutica Sciencia, 1(1), 98 - 106.

Tuomanen, E. 1986. Phenotypic tolerance: the search for $\beta$-lactam antibiotics that kill non-growing bacteria. Rev Infect Dis, 8 (Suppl. 3), S279-S291.

Tuomanen, E., Durack, D. T., Tomasz, A. 1986. Antimicrobial tolerance among clinical isolates of bacteria. Antimicrob Agents Chemother, 30(4), 521-527. http://dx.doi.org/10.1128/aac.30.4.521

Tzoulaki, I., Ebbels, T. M., Valdes, A., Elliott, P., Ioannidis, J. P. 2014. Design and analysis of metabolomics studies in epidemiologic research: a primer on $\begin{array}{llll}\text { omic technologies. } A m \quad J \text { Epidemiol, } & 180(2), & 129-39\end{array}$ https://doi.org/10.1093/aje/kwu143

Veenstra, T. D. 2012. Metabolomics: the final frontier. Genome Med, 4(4), 40 http://dx.doi.org/10.1186/gm339

Vogelman, B., Craig, W. A. 1986. Kinetics of antibacterial activity. J. Pediatr. 108(5 pt 2), 835 - 40. http://dx.doi.org/10.1016/S0022-3476(86)80754-5

Vosti, K. 1989. Serum bactericidal test: Past, Present and Future use in the management of patients with infections in: Remington, J. S., Swartz M. N. (eds) Current Clinical Topics in Infectious diseases. Philadelphia: Blackswell Scientific.

Wagner, H., Bladt, S. 2001. Plant Drug Analysis. A Thin Layer Chromatography Atlas. New York: Springer, 384p, ISBN: 3-540-58676-8

Walsh, C. 2000. Molecular mechanisms that confer antibacterial drug resistance. Nature, 406(6797), 775-781. http://dx.doi.org/10.1038/35021219

Washington, J. A. 1992. Clinical Microbiology In: Gorbach, S. L., Barlett, J. G, Blacklow, N. R. (eds). Infectious Diseases. Philadelphia: WB Saunders.

Wedge, D. E., Nagle, D. G. 2000. A new 2D-TLC bioautography method for the discovery of novel antifungal agents to control plant pathogens. J. Nat. Prod. 63(8), 1050-1054. http://dx.doi.org/10.1021/np990628r

Wollenweber, E. 1993. Flavones and flavonols In: The flavonoids, advances in research since 1986, Harborne, J. B. (ed.), London: Chapman and Hall.

World Health Organization 1978. The Promotion and Development of Traditional Medicine. Report of a WHO meeting. Technical report series 622 World Health Organization, Geneva.

World Health Organization 1977. Report of the W.H.O. Expert Committee on Antibiotics. Inform n. 26. Technical Report series n. 610, anexe 5 WHO, Geneva Yang, W., Chen, Y., Xi, C., Zhang, R., Song, Y., Zhan, Q., Bi, X., Abliz, Z 2013. Liquid chromatography tandem mass spectrometry-based plasma metabonomics delineate the effect of metabolites' stability on reliability of potential biomarkers. Anal Chem, 85(5), 2606-10. http://dx.doi.org/10.1021/ac303576b

Yin, P., Lehmann, R., Xu, G. 2015. Effects of pre-analytical processes on blood samples used in metabolomics studies. Anal Bioanal Chem, 407(17), 4879-92. http://dx.doi.org/10.1007/s00216-015-8565-x

Yousef, R. T., Tawil, G. G. 1966. Antimicrobial activity of volatile oils Pharmazie, 35(11), 4 -11.

Zarzycki, P. K., Zarzycka, M. B., Clifon, V. L., Adamski, J., Głod, B. K. 2011 Low-parachor solvents extraction and thermostated micro-thin-layer chromatography separation for fast screening and classification of spirulina from pharmaceutical formulations and food samples. J Chromatogr A, 1218(33), 5694-5704. http://dx.doi.org/10.1016/j.chroma.2011.06.065

Zohra, S. F., Meriem, B., Samira, S., Alsayadi Muneer, M.S. 2012. Phytochemical Screening and identification of some compounds from Mallow. $J$. Nat. Prod. Plant Resour., 2 (4), 512-516. 